\title{
Evaluation of Antidepressant Activity of Plocama pendula root extract
}

\author{
Authors \& Affiliation: \\ 1. Dr.Kuppala Manohar Babu. \\ 2. Pandrinki Geetha Mounika \\ 3. Rakurthi J S D Pawan kumar \\ 4. Nunna Priyanka \\ 5. Ayasetti Durga Sravani \\ VJ's College of pharmacy, \\ Diwancheruv, Rajahmundry.
}

\section{Corresponding Author}

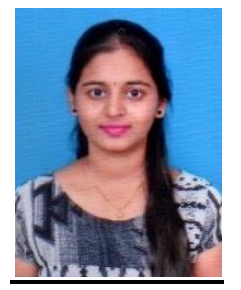

Pandrinki Geetha Mounika

(C) 2020.The Authors. Published under Caribbean Journal of Science and Technology

ISSN 0799-3757

http://caribjscitech.com/

\begin{abstract}
:
Plocama is a flowering plant genus belonging to Rubiaceae family. The natural products are soxlated from the dried powder of Plocama root with various solvents like $n$-Hexane, Ethyl acetate, Chloroform, Water and Ethanol. Phytochemical screening revealed that Alkaloids are present in chloroform extract where as Anthocyanins are present in ethanol extract. Terpenoids, Flavonoids, Alkaloids and Phenolic compounds are present in water extract.

In the present study, Plocama pendula root water extract (PPRWE) $(400 \mathrm{mg} / \mathrm{kg})$ produced significant antidepressant effect in Forced swim test \& Tail Suspension Test. Ecliptin alkaloid \& Culumbin, a flavonoid present in PPRWE may be facilitating mono aminergic transmission there by producing antidepressant effects. In this work, it was demonstrated that the administration of different doses of the water extract of Plocama pendula root in mice was able to induce antidepressant effects. On the basis of the clinical association of depressive episodes and stressful life events, many of the animal models for the evaluation of antidepressant drug activity assess stress-precipitated behaviors. Results of this study showed that the administration of the PPRWE produced a diminution of immobility time of mice exposed to the both forced swimming and tail suspension tests.

Harmaline alkaloids present in Plocama pendula act as reversible monoamine oxidase inhibitors and in common with other beta carboline binds to 5-Hydroxy Tryptamine receptors. Inhibition of this enzyme causes a reduction in metabolism and subsequent increase in the concentration of biogenic amines. The flavonoid components of PPRWE might be interacting with adrenergic and serotonergic systems in mediating the antidepressant effects of PPRWE. However, the precise mechanisms by which the extract produced antidepressant-like effect are not completely understood. Further studies would be necessary to evaluate the contribution of active chemical constituents for the observed antidepressant activity.
\end{abstract}

Keywords: Plocama pendula, Antidepressant Activity, Forced Swim Test, Tail Suspension Test. 


\section{Introduction:}

Plocama is a genus of flowering plants in the family Rubiaceae. It was described by William Aiton in 1789. It is distributed from the Canary Islands to northwestern India [1]. The genus was expanded in 2007 when several other Rubiaceae genera were merged into it. There are now about 34 species.[2]. Plants of this genus are herbs or shrubs. They generally have an offensive scent when crushed. The leaves are oppositely arranged. The corolla is funnel shaped with a short to long tubular base. The fruit is either a drupe or a body that splits into two parts when ripe[2].

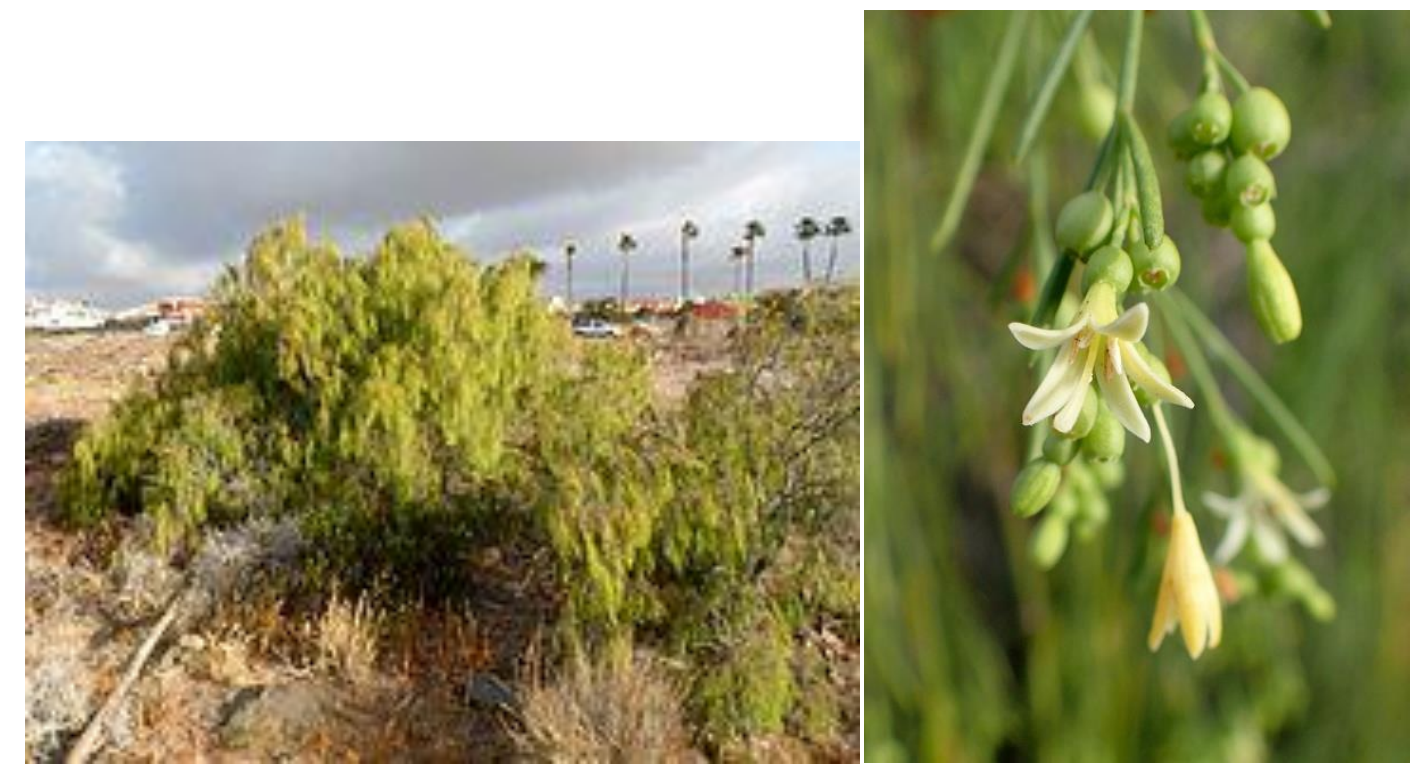

Image.1 Plocamapendula

\begin{tabular}{|l|l|}
\hline Kingdom: & Plantae \\
\hline Order: & Asterids \\
\hline Family: & Rubiaceae \\
\hline Genus: & Plocama \\
\hline Species: & P. pendula \\
\hline Binomial name: & PlocamaPendula \\
\hline \hline
\end{tabular}

Table.2 Scientific data of Plocamapendula

Plocamapendula is a species of flowering plant in the coffee family Rubiaceae, endemic to the Canary islands.[1][2]:260 It is a shrub growing up to $2 \mathrm{~m}$ ( $6 \mathrm{ft} 7 \mathrm{in}$ ), with fili form (very narrow leaves) and minute flowers grouped near the tips of slender, pendulous branches. The fruit is a black berry.[2]

This species is a shrub or small tree that is endemic to the Canary Islands, where it can be frequently found across its range. Its habitat is mainly xerophytic scrubs over coastal areas and mid-altitude slopes. Although suitable habitat for this species has been negatively affected by urban development, invasive species and other impacts, the situation has not reached a point where the conservation status of this species is threatened. The species is thus assessed as Least Concern. The introduction and rapid spread of the exotic species Acacia farnesiana could become a factor to be considered in the future. Confirmation of its current presence and distribution on some of the islands is required.

This species is a shrub or small tree that is endemic to the Canary Islands, where it can be frequently found across its range. Its habitat is mainly xerophytic scrubs over coastal areas and mid-altitude slopes. Although suitable habitat for this species has been negatively affected by urban development, invasive species and other impacts, the situation has not reached a point where the conservation status of this species is threatened. The species is thus assessed as 
Least Concern. The introduction and rapid spread of the exotic species Acacia farnesiana could become a factor to be considered in the future. Confirmation of its current presence and distribution on some of the islands is required.

This species is endemic to the Canary Islands, where it is found on all the islands except Lanzarote (Gobierno de Canarias 2017), although its presence in El Hierro and La Palma requires confirmation. The extent of occurrence (EOO) of the wild populations of the species is estimated to be about $39,046 \mathrm{~km}^{2}$, including El Hierro and La Palma (Gobierno de Canarias 2017) and the area of occupancy (AOO) has been calculated to be close to 1,700 $\mathrm{km}^{2}$ (Gobierno de Canarias 2017). It occurs from 50 to $500 \mathrm{~m}$ above sea level (Dirección General de Protection de la Naturaleza 2011), and even up to $700 \mathrm{~m}$ a.s.l.

There is little information regarding the population of this species although it is considered abundant throughout its distribution and the trend is assumed to be stable.

This is a shrub or small tree that can grow up to 4 to $5 \mathrm{~m}$ in height. It is found in xerophytic scrubs in coastal areas, in cliffs and hill slopes with rocky soils and plenty of sun exposure, and along the margins and channels of ravines (Kunkel 1981). Although suitable habitat for this species has been negatively affected by urban development, the situation has not reach a point where the conservation status of this species is threatened [3]. The fruit of this species is an important part of the summer diet of birds and reptiles such as sylviid warblers (Sylvia spp.) and lacertid lizards (Gallotia spp.) (Valido and Nogales, cited by Dennis et al. 2007), which act as seed dispersers. Invasive species are also related to $P$. pendula. In Tenerife by the European rabbit (Oryctogaluscuniculus) (Nogales et al. 1995, 1996); and in all of the islands by the feral cat (Feliscatus) (Nogales et al. 1996).

Given its resistance to drought, this species can be used in the re-vegetation of lower and dryer regions of the Canary Islands (Dirección General de Protección de la Naturaleza 2011). It has been traditionally used as a natural coloring element (Pérez de Paz and Hernández Padrón 1999).

Some of the known locations are found in protected areas in the Canary Islands (Protected Planet 2017). According to BGCI (2017) there are no ex situ collections of this species in botanic gardens worldwide. No other conservation actions needed have been identified [3].

\section{Materials and Methods:}

\section{Preparation of plant root extract:}

The collected PlocamaPendula roots were dried under shade, powdered and sieved through 40mesh. About 100g of powdered materials were extracted with petroleum ether $\left(60^{\circ}-80^{\circ} \mathrm{C}\right)$ using soxhlet apparatus. The extraction was carried out until the extractive becomes colorless. The extracts is then concentrated and dried under reduced pressure. The solvent free semisolid mass thus obtained is dissolved in tween 80 and used for the experiment.

The list of chemicals and equipment with make are showed in Table.1 and Table.2. All reagents are analytical grade. Required animals are purchased from Raaj Farms, Shastri Nagar, Chennai, India.

\begin{tabular}{|l|l|l|}
\hline \multicolumn{1}{|c|}{ S.No } & \multicolumn{1}{|c|}{ Equipment } & \multicolumn{1}{|c|}{ Make } \\
\hline 1 & Electronic balance & Denver \\
\hline 2 & Spectrophotometer & TECH CHOMP \\
\hline 3 & $\begin{array}{c}\text { Tail Suspension } \\
\text { Test apparatus }\end{array}$ & HA 76-0783 \\
\hline 4 & Forced swim test & 2. ANY-MAZE \\
\hline
\end{tabular}

Table.2 List of Equipment 


\begin{tabular}{|c|c|c|}
\hline S.No & Equipment & Make \\
\hline 1 & Sulphuric acid & SD Fine (Analytical Grade) \\
\hline 2 & Ferrous chloride & Merck (Analytical Grade) \\
\hline 3 & Ammonia & Merck (Analytical Grade) \\
\hline 4 & Lead Acetate & SD Fine (Analytical Grade) \\
\hline 5 & Ferric chloride & SD Fine (Analytical Grade) \\
\hline 6 & Hydrochloric acid & Merck (Analytical Grade) \\
\hline 7 & Barfoed's reagent & Merck (Analytical Grade) \\
\hline 8 & Molisch's reagent & Merck (Analytical Grade) \\
\hline 9 & Fehling-B reagent & Merck (Analytical Grade) \\
\hline 10 & Fehling $-\mathrm{A}$ reagent & Merck (Analytical Grade) \\
\hline 11 & Pricric acid & SD Fine (Analytical Grade) \\
\hline 12 & Potassium iodide & SD Fine (Analytical Grade) \\
\hline 13 & Potassium bismuth iodide & Merck (Analytical Grade) \\
\hline 14 & Chloroform & Merck (Analytical Grade) \\
\hline 15 & Sodium chloride & SD Fine (Analytical Grade) \\
\hline 16 & Glacial acetic acid & SD Fine (Analytical Grade) \\
\hline 17 & Chlorosulfonic acid & Merck (Analytical Grade) \\
\hline 18 & Zinc chloride & SD Fine (Analytical Grade) \\
\hline 19 & Acetic anhydride & Merck (Analytical Grade) \\
\hline 20 & Alloxan & Sigma-Aldrich \\
\hline 21 & EDTA - & SD Fine (Analytical Grade) \\
\hline 22 & $\mathrm{KCl}-$ & SD Fine (Analytical Grade) \\
\hline 23 & $\mathrm{HCl}$ & SD Fine (Analytical Grade) \\
\hline 24 & Fluoxetine hydrochloride & Cadila Pharmaceuticals Ltd. \\
\hline 25 & Imipramine hydrochloride & Lupin Ltd \\
\hline 26 & Diazepam & Biomed Pharma \\
\hline
\end{tabular}

\section{Table.3 List of chemicals}

\section{Preparation of plant root extract:}

The collected Plocama Pendula roots were dried under shade and powdered by a mechanical grinder, sieved through 40 mesh. About $100 \mathrm{~g}$ of powdered materials were extracted with petroleum ether $\left(60^{\circ}-80^{\circ} \mathrm{C}\right)$ using soxhlet apparatus. The extraction was carried out until the extractive becomes colorless. The extracts is then concentrated and dried under reduced pressure. The solvent free semisolid mass thus obtained is dissolved in tween 80 and used for the experiment.

\section{Preliminary phytochemical screening:}

\section{Test for steroids:}

Salkowski Test: Few drops of concentrated sulphuric acid are added to the plant extract, shaken and on standing; lower layer turns red in color.

Liebermann Burchard's Test: To the extract, few drops of acetic anhydride is added and mixed well. $1 \mathrm{ml}$ of concentrated sulphuric acid is added from the sides of test tube, a reddish brown ring is formed at the junction of two layers.

\section{Tests for triterpenoids:}

Salkowski Test: Few drops of concentrated sulphuric acid is added to the extract, shaken and on standing, lower part turns golden yellow colour.

Lieberman Burchard's Test: To the extract, few drops of acetic anhydride is added and mixed well. $1 \mathrm{ml}$ of concentrated sulphuric acid is added from the sides of test tube, a red ring indicates triterpenes.

Ischugajiu Test: Excess of acetylchloride and pinch of zinc chloride are added to the extract solution, Kept aside for reaction to subside and warmed on water bath, cosin red colour is produced. 
Brickorn and Brinar Test: To the extract, few drops of chloro sulfonic acid in glacial acetic acid (7:3) are added, red colour is produced.

\section{Test for Saponins:}

Foam Test: Small amount of extract is shaken with little quantity of water, the foam produced persists for 10 minutes. It confirms the presence of saponins.

Haemolysis Test: To $2 \mathrm{ml}$ of $1.8 \%$ Sodium chloride solution in two test tubes, $2 \mathrm{ml}$ distilled water is added to one and $2 \mathrm{ml}$ of $1 \%$ extract to the other, 5 drops of blood is added to each tube and gently mixed with the contents. Haemolysis observed under the microscope in the tube containing the extract indicates the presence of saponins

\section{Test for Steroidal Saponin:}

The extract is hydrolysed with sulphuric acid and extracted with chloroform. The chloroform layer is tested for steroids.

\section{Tests for Triterpenoidal Saponin:}

The extract is hydrolyzed with sulphuric acid and extracted with chloroform. The chloroform layer is tested for triterpenoids

\section{Tests for Alkaloids}

Mayer's Test: The acid layer when mixed with Mayer's reagent (Potassium mercuric iodide solution) gives creamy white precipitate

Dragendroff's Test: The acid layer with few drops of Dragendroff's reagent (Potassium bismuth iodide) gives reddish brown precipitate.

Wagner's Test: The acid layer when mixed with few drops of Wagner's reagent (solution of iodide in potassium iodide) gives brown to red precipitate

Hager's Test: The acid layer when mixed with few drops of Hager's reagent (Saturated solution of pricric acid) gives yellow colored precipitate.

7 Tests for Carbohydrates:

Fehlings's Test: The extract when heated with Fehling's A and B solutions gives an orange red precipitate showing the presence of reducing sugar.

Molischs's Test: The extract is treated with Molisch's reagent and conc .sulphuric acid along the sides of the test tube, a reddish violet ring shows the presence of carbohydrate.

Benedict's test: The extract on heating with Benedict's reagent, brown precipitate indicates the presence of sugar.

Barfoed's Test: Barfoed's reagent is added and boiled on water bath for few minutes, reddish precipitate is observed for the presence of carbohydrate.

8. Test for Flavonoids:

Shinoda Test: The extract solution with few fragments of magnesium ribbon and concentrated hydrochloric acid produced magenta color after few minutes.

Ferric chloride test: Alcoholic solution of extract reacts with freshly prepared ferric chloride solution and given blackfish green color

Lead Acetate Test: Alcoholic solution of extract reacts with 10\% lead acetate solution and given yellow precipitate.

9. Test for Glycosides:

Anthraquinone test: Drug is powdered and extracted with either ammonia or caustic soda. The aqueous layer shows pink color

Keller-killiani test: This is for cardiac glycosides. The extract and 0.4 glacial acetic acid are mixed with ferrous chloride and $0.5 \mathrm{mi}$ of concentrated sulphuric acid. The acetic acid layer shows blue color 


\section{Test for Phenolic Compounds:-}

Ferric chloride test:-Treat the extract with ferric chloride solution then blue color appears if hydrolysable tannins are present and green color appears if condensed tannins are present.

Gelatin test: - To the test solution add $1 \%$ gelatin solution containing $10 \% \mathrm{NaCl}$, and then ppt is formed.

Test for chlorogenic acid:-Treat the test solution with aqueous ammonia and expose to air gradually, green colour is developed.

\section{Antidepressant Activity of Plocama Pendulaplant root extract: Acute toxicity study:}

Animals were observed for four hours hourly for behavior changes and daily for six days. The extract was devoid of any toxicity in rats when given in dose up to $500 \mathrm{mg} / \mathrm{kg}$ by oral route. Hence, for further studies $100,200,400 \mathrm{mg} / \mathrm{kg}$ doses of extract were used.

Acute toxicity study was done according to OECD (Organization for Economic Co-operation and Development) Guideline, fixed dose method; with starting dose of $2000 \mathrm{mg} / \mathrm{kg}$ body weight was adopted. Starting dose of $2000 \mathrm{mg} / \mathrm{kg}$ (per oral) of each was given to 5 animals, animals were kept for observation of behavioral change and death up to $72 \mathrm{~h}$.

\section{Animals}

Male Swiss albino mice weighing between $25-30 \mathrm{~g}$ were used for the present study. The experiment animals were maintained under standard environmental conditions i.e $25^{\circ}-27^{\circ} \mathrm{C}$ and relative humidity. Standard pellet diet provided and water and libitum.

\section{Experimental protocols}

Overnight fasted 42 mice were selected randomly, 42 animals are divide in to Seven groups i.e A,B,C,D,E.F,G Each group having six animals. On the day of experiment for administration of vehicle, standard drug and study drugi.e PPRWE (Plocama Pendula root water extract). The animals were acclimatized one hour before for behavioral tests. Thirty minutes and 1 hour time interval between drug administration and behavioral tests were maintained in case of intra peritoneal and oral administrations respectively.

\begin{tabular}{|l|l|}
\hline \multicolumn{1}{|c|}{ Group No (n=6) } & \multicolumn{1}{c|}{ Drug and Dose } \\
\hline Group A & Control, received distilled water \\
\hline Group B & Imipramine $15 \mathrm{mg} / \mathrm{kg}$ \\
\hline Group C & Fluoxetine $20 \mathrm{mg} / \mathrm{kg}$ \\
\hline Group D & Diazepam $1 \mathrm{mg} / \mathrm{kg}$ \\
\hline Group E & PPRWE $100 \mathrm{mg} / \mathrm{kg}$ \\
\hline Group F & PPRWE $200 \mathrm{mg} / \mathrm{kg}$ \\
\hline Group G & PPRWE $400 \mathrm{mg} / \mathrm{kg}$ \\
\hline
\end{tabular}

Table. 4 Drug and dosage

The antidepressant activity was carried out using two different models. Further the effect of drugs was evaluated in open field test.

\section{Forced Swim Test:}

Forced Swim Test (FST): FST or behavior despair was proposed as a model to test for antidepressant activity by Porsolt et al[5]. Depression was produced by forcing the animal to swim individually in a glass jar containing fresh water of $15 \mathrm{~cm}$ height and maintained at $25 \mathrm{oC}$. This constituted pretest session. Twenty-four hour later each animal was again forced to swim. After an initial $2 \mathrm{~min}$ period of vigorous activity, each animal assumed a typical immobile posture. The total duration of immobility was recorded in next $4 \mathrm{~min}$ of a total $6 \mathrm{~min}$ test. The change in the immobility period was calculated after administering drugs to the groups as mentioned in the above table. 
For the forced swim test (FST), Rats of either sex were individually forced to swim in an open cylindrical container (diameter $10 \mathrm{~cm}$, height $25 \mathrm{~cm}$ ) containing $19 \mathrm{~cm}$ of water at $25 \pm 1^{\circ} \mathrm{c}$. Treatment was given $60 \mathrm{~min}$ prior to study as described by study design. All animals were forced to swim for $6 \mathrm{~min}$ and the duration of immobility was observed and measured during the final $4 \mathrm{~min}$ interval of the test. Each mouse was judged to be immobile when it ceased struggling and remained floating motionless in the water, making only those movements to keep its head above water. A decrease in the duration of immobility is indicative of an antidepressant like effect. Results are showed in Table.6

\section{Tail Suspension Test:}

The total duration of immobility induced by tail suspension was measured according to the method described by Steru et al [6] Depression was produced by suspending the animal from the edge of a table $50 \mathrm{~cm}$ above the floor by an adhesive tape placed approx. $1 \mathrm{~cm}$. from the tip of the tail. Immobility time was recorded during a 6 min. period. Changes in the immobility duration were studied after administering drugs in separate groups of animals.

The antidepressant activity was expressed as reduction in the immobility duration between the control, standard and animals treated with test drug.

Treatment was given 60 min prior to study as described by study design. Mice were suspended on the edge of the table, $50 \mathrm{~cm}$ above the floor, with the help of adhesive tape placed approximately $1 \mathrm{~cm}$ from the tip of the tail. The total duration of immobility induced by tail suspension was recorded during a $6 \mathrm{~min}$ of the $10 \mathrm{~min}$ period. Animal was considered to be immobile when it did not show any movement of the body, hanged passively and completely motionless. Results are showed in Table.7

\section{Results and Discussion:}

Plocama pendula roots are dried under shade and roots were dried and powdered. 250 grms of leaves powdered packed for soxlate extraction. The chemical constituents are collected in Hexane, Ethyl acetate, Chloroform, Water and Ethanol. The Yield of extract was showed in Table.5. The collected extract was screened for the identification of phyto chemicals. The results are showed in Table.5

\begin{tabular}{|c|c|c|c|c|c|}
\hline Compound & $\begin{array}{c}\text { Hexane } \\
\text { Extraction }\end{array}$ & $\begin{array}{l}\text { Ethyl Acetate } \\
\text { Extraction }\end{array}$ & $\begin{array}{c}\text { Chloroform } \\
\text { Extract }\end{array}$ & $\begin{array}{c}\text { Water } \\
\text { Extraction }\end{array}$ & $\begin{array}{l}\text { Ethanol } \\
\text { Extract }\end{array}$ \\
\hline Steroids & - & - & - & - & - \\
\hline Terpenoids & - & - & - & + & \\
\hline Flavonoids & - & - & - & + & - \\
\hline Alkaloids & - & - & + & + & - \\
\hline Fatty Acids & - & - & - & - & - \\
\hline $\begin{array}{c}\text { Phenolic } \\
\text { compounds }\end{array}$ & - & - & - & + & - \\
\hline Carrotinoids & - & - & - & - & - \\
\hline Saponins & - & - & - & - & - \\
\hline Tanis & - & - & - & - & - \\
\hline Polyuronides & - & - & - & - & - \\
\hline Chlorogenic acid & - & - & - & - & - \\
\hline Anthocyanins & - & - & - & - & + \\
\hline $\begin{array}{l}\text { Anthocyanin } \\
\text { glycosides }\end{array}$ & - & - & - & - & - \\
\hline Amino acids & - & - & - & - & - \\
\hline
\end{tabular}




\begin{tabular}{|l|c|c|c|c|c|}
\hline $\begin{array}{l}\text { Weight of collected } \\
\text { plant extract (grms) }\end{array}$ & 7.25 & 2.62 & 3.74 & 6.45 & 1.26 \\
\hline$\%$ of yield & 2.9 & 1.04 & 1.49 & 2.58 & 0.5 \\
\hline
\end{tabular}

Table.5Phyto chemical screening results

In phyto chemical screening most of the chemical constituents are present in water and Methonlic extract. Alkaloids are present in chloroform extract and Anthocyanins are present in methanol extract. Terpenoids, Flavonoids, Alkaloids, Phenolic compounds are present in water extract.

\section{Antidepressant Activity:}

In the present study, PPRWE (400 mg/kg) produced significant antidepressant effect in in Forced swim test \& Tail Suspension Test. These models of depression are widely used to screen new antidepressant drugs. The tests are quite sensitive and relatively specific to all major classes of antidepressant drugs including TCAs, SSRIs, MAOI, and A typical antidepressants. The forced swimming test is the most widely used tool for assessing antidepressant activity pre-clinically. The widespread use of this simple model is mainly due to its ability to detect a broad spectrum of antidepressant agents. It has been argued that Tail Suspension Test is less stressful than Forced swim test and has greater pharmacological sensitivity. Environmental factors and hereditary factors play a major role in producing deficient monoaminergic transmission in central nervous system thereby producing symptoms of depression. Ecliptin alkaloid \&Culumbin, a flavnoid present in PPRWE may be facilitating monoaminergic transmission there by producing antidepressant effects.

Forced Swim Test:

\begin{tabular}{|l|l|l|l|l|}
\hline Group No (n=6) & Drug and Dose & \multicolumn{2}{|c|}{ Immobility Period (Secs) } \\
\cline { 3 - 5 } & & Pre Treatment & $\begin{array}{l}\text { Post Treatment (7 } \\
\text { Days) }\end{array}$ & $\begin{array}{l}\text { Post Treatment } \\
\text { (14 Days) }\end{array}$ \\
\hline Group A & & & $189.5 \pm 0.4$ & $189.2 \pm 0.2$ \\
& $\begin{array}{l}\text { Control, received } \\
\text { distilled water }\end{array}$ & $190.2 \pm 0.6$ & $145.2 \pm 1.46$ & $140.2 \pm 0.45$ \\
\hline Group B & Imipramine $15 \mathrm{mg} / \mathrm{kg}$ & $196.4 \pm 1.4$ & $125.7 \pm 0.49$ & $119.5 \pm 0.36$ \\
\hline Group C & Fluoxetine $20 \mathrm{mg} / \mathrm{kg}$ & $190.2 \pm 0.56$ & $124.55 \pm 1.2$ & $115 \pm 0.42$ \\
\hline Group D & Diazepam $1 \mathrm{mg} / \mathrm{kg}$ & $188.5 \pm 1.6$ & $185.2 \pm 1.64$ & $179.4 \pm 1.22$ \\
\hline Group E & PPRWE 100 mg/kg, & $194.8 \pm 1.24$ & $162.5 \pm 0.68$ & $155.7 \pm 1.32$ \\
\hline Group F & PPRWE 200 mg/kg & $190.6 \pm 1.96$ & $159.5 \pm 1.43$ & $145.6 \pm 0.20$ \\
\hline Group G & PPRWE 400 mg/kg & $193.3 \pm 0.42$ & & \\
\hline
\end{tabular}

Table 6: Effect of PPRWE on Immobility Period (Seconds) of rats using Forced Swim Test 


\begin{tabular}{|l|l|l|l|l|l|}
\hline \multirow{2}{*}{$\begin{array}{l}\text { Group } \\
(\mathrm{n}=6)\end{array}$} & Drug and Dose & \multicolumn{3}{|l|}{} \\
\cline { 3 - 6 } & & $\begin{array}{l}\text { Pre } \\
\text { Treatment }\end{array}$ & $\begin{array}{l}\text { Post } \\
\text { Treatment } \\
\mathbf{4} \text { Days })\end{array}$ & $\begin{array}{l}\text { Post Treatment } \\
\text { (7 Days) }\end{array}$ & $\begin{array}{l}\text { Post } \\
\text { Treatment } \\
(14 \text { Days })\end{array}$ \\
\hline Group A & $\begin{array}{l}\text { Control, received distilled } \\
\text { water }\end{array}$ & $191.4 \pm 1.45$ & $189.8 \pm 0.28$ & $188.2 \pm 0.65$ & $186.4 \pm 0.49$ \\
\hline Group B & Imipramine 15mg/kg & $189.6 \pm 0.24$ & $188.2 \pm 1.23$ & $120.4 \pm 0.54$ & $115.6 \pm 0.53$ \\
\hline Group C & Fluoxetine 20 mg/kg & $190.2 \pm 0.62$ & $189.3 \pm 1.45$ & $125.2 \pm 0.56$ & $120.9 \pm 1.66$ \\
\hline Group D & Diazepam (DZP) 1mg/kg & $191.6 \pm 0.25$ & $190.5 \pm 1.62$ & $130.6 \pm 0.29$ & $128.4 \pm 1.42$ \\
\hline Group E & PPRWE 100 mg/kg, & $189.2 \pm 0.86$ & $188.6 \pm 1.8$ & $150.2 \pm 0.41$ & $148.6 \pm 1.09$ \\
\hline Group F & PPRWE 200 mg/kg & $190.2 \pm 0.93$ & $189.4 \pm 1.05$ & $145.7 \pm 0.69$ & $140.2 \pm 0.36$ \\
\hline Group G & PPRWE 400 mg/kg & $191.1 \pm 0.19$ & $190.2 \pm 1.33$ & $140.4 \pm 0.85$ & $135.6 \pm 0.44$ \\
\hline
\end{tabular}

Table 7: Effect of PPRWE on immobility period (seconds) of rats using tail suspension test

The incidence of anxiety and depression in the community is very high and is associated with lot of morbidity. Hence, it is very important to address these problems and find effective remedies.

Though several drugs are available, all are associated with some limitations and there is an urgent need for alternative medications for these disorders. The use of Plocama pendula for treating nervous disorders, there is an absence of scientific reports about the evaluation of its pharmacological effects.

In this work, it was demonstrated that the administration of different doses of the water extract of Plocamapendula root in mice was able to induce antidepressant effects. On the basis of the clinical association of depressive episodes and stressful life events, many of the animal models for the evaluation of antidepressant drug activity assess stress-precipitated behaviors.

The two most widely used animal models for antidepressant screening are the forced swimming and tail suspension tests. These tests are quite sensitive and relatively specific to all major classes of antidepressants. In Tail Suspension Test, immobility reflects a state of despair which can be reduced by several agents which are therapeutically effective in human depression.

Similarly in the FST, mice are forced to swim in restricted space from which they cannot escape. This induces a state of behavioral despair in animals, which is claimed to reproduce a condition similar to human depression. It has been seen that the Tail Suspension Test is less stressful and has higher pharmacological sensitivity than Forced swim test. Results showed that the administration of the PPRWE produced a diminution of immobility time of mice exposed to the both forced swimming and tail suspension tests.

In the present study, PPRWE (100, 200 and $400 \mathrm{mg} / \mathrm{kg}$ ) administered to mice, produced significant antidepressant-like effect in both Tail Suspension Test and Forced swim test and their efficacies were found to be comparable to Imipramine $(15 \mathrm{mg} / \mathrm{kg})$ and Fluoxetine $(20 \mathrm{mg} / \mathrm{kg})$. 
Data in the literature demonstrated that drugs that alter general motor activity may give false-positive/negative results in the forced swimming test. The effects produced by PPRWE and DZP $(1.0 \mathrm{mg} / \mathrm{kg})$ upon the open field test demonstrated that these products do not modify the spontaneous locomotor activity of mice, which indicates that the plant extract exerts antidepressant effects without modifying significantly this parameter. Therefore, it is probable that these effects are not related to the stimulation of general motor activity. It has been established that the shortening of immobility time in the forced swimming and the tail suspension tests depends mainly on the enhancement of central 5-HT and catecholamine neurotransmission.

Early evidence of a role for noradrenaline in depression came from the discovery that drugs, either causing or alleviating depression, acted to alter the noradrenaline metabolism. Furthermore, depletion studies carried out in treated and untreated patients indicated a role for serotonin and noradrenaline in depression. Harmaline alkaloids present in Plocamapendula act as reversible monoamine oxidase inhibitors and in common with other beta carboline binds to 5-Hydroxy Tryptaminereceptors. MAO regulates the metabolic degradation of catecholamines, serotonin and other endogenous amines in central nervous system. Inhibition of this enzyme causes a reduction in metabolism and subsequent increase in the concentration of biogenic amines. Also the flavonoid components of PPRWE might be interacting with adrenergic and serotonergic systems in mediating the antidepressant effects of PPRWE. However, the precise mechanisms by which the extract produced antidepressant-like effect are not completely understood. Further studies would be necessary to evaluate the contribution of active chemical constituents for the observed antidepressant activity as it still remains to be determined which components were responsible for these effects.

\section{Conclusion:}

Hence Plocama pendula roots possesses antidepressant effect in animal models of depression which was comparable to that of Imipramine and Fluoxetine as demonstrated in this study. The phyto chemical analysis, separation of active ingredients and further investigation in this line is essential to establish its therapeutic benefits.

\section{References:}

1. Requena Suarez, D.K. \& Rivers, M.C. 2017. Plocamapendula. The IUCN Red List of Threatened Species 2017: e.T104191669A104191685.

2. "World Checklist of Rubiaceae". Retrieved 17 January 2017.

3. Backlund, M., Bremer, B., \&Thulin, M. (2007). Paraphyly of Paederieae, recognition of Putorieae and expansion of Plocama (Rubiaceae-Rubioideae). Taxon, 56(2), 315-328.

4. Braulio M. Fraga, Carmen E. Díaz, and Nayra Quintana, Triterpenes from Natural and Transformed Roots of Plocamapendula, J. Nat. Prod., 2006, 69 (7), pp 1092-1094

5. Porsolt RD, Bertin. A, Behaviour despair in mice: A primary screening test for antidepressants .Archives Internationales de Pharmacodynamie et de therapie 1977;229:327-36

6. Steru. L, Chemat. R, The tail suspension test: A novel method for screening antidepressants in mice. Psychopharmacology 1985;85:367-70

7. Steru. L, Chemat. R, The tail suspension test: A novel method for screening antidepressants in mice. Psychopharmacology 1985;85:367-70

8. Vikasgupta, P.bansal, P.kumar, R.shri:Anxiolytic and antidepressant activities of different extracts from Citrus paradisi var. Duncan Asian journal of pharmaceutical \&clinical research :Vol.3 Issue 2, April-June 2010

9. D. Dhingra, A. Sharma et al. Alt \&complementary therapies,Feb2005(51-52)

10. M. Jesupillai, S. Jasemine, M. Palanivelu. Diuretic activity of leaves of Erythrinaindica Lam. International Journal of Green Pharmacy. October-December 2008:218.

11. Dhingra D and Sharma A. Antidepressant-like activity of Glycyrrhizaglabra. Neuro psycho pharmacolBiol Psychiatry2006; 30: 449. 
12. Rogoz Z, Skuza G, Khodzinska A. Anxiolytic like effects of the preferential dopamine D3 receptor agonists in an animal model. Pol J Pharmacol 2003; 55 (3):449-454.

13. Porsolt RD, Bertin A and Jalfre M. Behavioral despair in mice: a primary screening test for antidepressants. Archives Internationales de Pharmaco dynamie et de Therapie 1977;229: 327.

14. Willner P. The validity of animal models of depression .Psychopharmacology 1984; 83: 1 .

15. Thierry B, Steru L, Simon $\mathrm{P}$ and Porsolt RD. The tail suspensiontest: ethical considerations. Psychopharmacology 1986; 90:284.Novas ML, Wolfman C, Medina JH, De Robertis E. Proconvulsant and anxiogenic effects of n-butyl-h-carboline-3-carboxylate, onendogenous benzodiazepine binding inhibitor from brain. Pharmacol Biochem Behav 1988; 30: 331-6.

16. Borsini F, Meli A. Is the forced swimming test a suitable model for revealing antidepressant activity? Psychopharmacology(Berl.) 1988; 94: 147-60. 